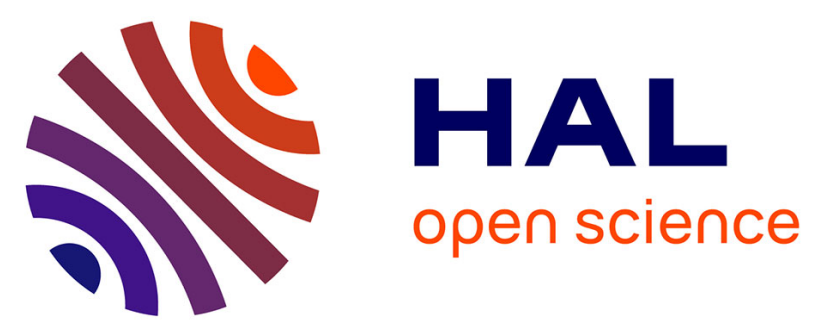

\title{
In vitro antibacterial activity of doripenem against clinical isolates from French teaching hospitals: proposition of zone diameter breakpoints
}

C. Lascols, P. Legrand, A. Mérens, R. Leclercq, L. Armand-Lefevre, H. B. Drugeon, M. D. Kitzis, C. Muller-Serieys, M. E. Reverdy, M.

Roussel-Delvallez, et al.

\section{To cite this version:}

C. Lascols, P. Legrand, A. Mérens, R. Leclercq, L. Armand-Lefevre, et al.. In vitro antibacterial activity of doripenem against clinical isolates from French teaching hospitals: proposition of zone diameter breakpoints. European Journal of Clinical Microbiology and Infectious Diseases, 2010, 30 (4), pp.475-482. 10.1007/s10096-010-1117-6 . hal-00642845

\section{HAL Id: hal-00642845 \\ https://hal.science/hal-00642845}

Submitted on 19 Nov 2011

HAL is a multi-disciplinary open access archive for the deposit and dissemination of scientific research documents, whether they are published or not. The documents may come from teaching and research institutions in France or abroad, or from public or private research centers.
L'archive ouverte pluridisciplinaire HAL, est destinée au dépôt et à la diffusion de documents scientifiques de niveau recherche, publiés ou non, émanant des établissements d'enseignement et de recherche français ou étrangers, des laboratoires publics ou privés. 
1 In vitro antibacterial activity of doripenem against clinical isolates from

2 French teaching hospitals. Proposition of zone diameters breakpoints

$4 \quad$ Running title: doripenem, in vitro activity, breakpoints

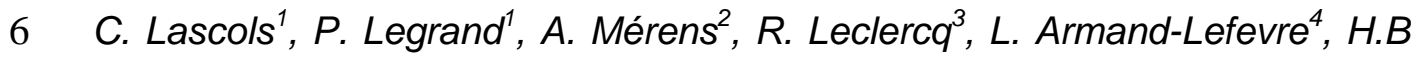

7 Drugeon $^{5}$, M.D. Kitzis ${ }^{6}$, C. Muller-Serieys ${ }^{4}$, M.E. Reverdy ${ }^{7}$, M. Roussel-

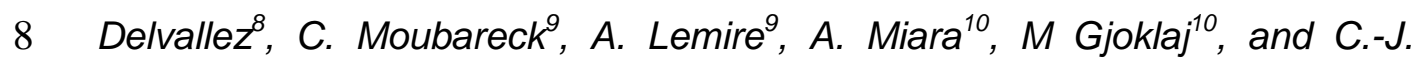

9 Soussy ${ }^{1}$.

$11{ }^{1}$ Service de Bactériologie-Virologie-Hygiène, CHU Henri Mondor, Assistance

12 Publique-Hôpitaux de Paris, Université Paris 12, Créteil, ${ }^{2}$ Laboratoire de

13 Biologie Médicale, Hôpital d'Instruction des Armées Begin, Saint Mandé,

$14{ }^{3}$ Laboratoire de Microbiologie, CHU Côte de Nacre, Caen, ${ }^{4}$ Laboratoire de

15 Bactériologie et Virologie, CHU Bichat, Assistance Publique-Hôpitaux de 16 Paris, Paris, ${ }^{5}$ Laboratoire de Bactériologie, CHU Guillaume et René Laennec,

17 Nantes, ${ }^{6}$ Service de Microbiologie Médicale, Hôpital Saint-Joseph, Assistance

18 Publique-Hôpitaux de Paris, Paris, ${ }^{7}$ Laboratoire Central de Microbiologie,

19 CHU Edouard Herriot, Lyon, ${ }^{8}$ Laboratoire de Bactériologie et Virologie, CHRU

20 Calmette, Lille, France, ${ }^{9}$ Unité des Agents Antibactériens, Centre National de

21 Référence de la Résistance aux Antibiotiques (CRAB), Institut Pasteur, Paris,

$22{ }^{10}$ Janssen-Cilag, Issy-Les-Moulineaux, France.

24 Corresponding author: Christine LASCOLS, CHU Henri Mondor, Assistance 25 Publique-Hôpitaux de Paris, Université Paris 12, 51 Avenue du Marechal de 26 Lattre de Tassigny, 94010 CRETEIL Cedex, France. Email: 27 c.lascols@gmail.com 


\section{Lascols}

ABSTRACT

31 Purpose: The aims of the study were to determine the in vitro activity of doripenem, a new carbapenem, against a large number of bacterial pathogens and to propose zone diameter breakpoints for clinical categorization in France according to the EUCAST MIC breakpoints.

Methods: MICs of doripenem were determined by broth microdilution method against 1547 clinical isolates from 8 French hospitals. Disk diffusion test was performed (10- $\mu \mathrm{g}$ discs) according to the CASFM method.

Results: $\mathrm{MIC}_{50 / 90}(\mathrm{mg} / \mathrm{L})$ values were as follows: methicillin-susceptible $S$. aureus (MSSA) (0.03/0.25), methicillin-resistant $S$. aureus (1/2) (MRSA), methicillin-susceptible coagulase-negative staphylococci (MSCoNS)

$41(0.03 / 0.12)$, MRCoNS (2/8), S. pneumoniae (0.016/0.25), viridans group 42 streptococci $(0.016 / 2)$, B-haemolytic streptococci $(\leq 0.008 / \leq 0.008)$, E. faecalis 43 (2/4), E. faecium (128/>128), Enterobacteriaceae (0.06/0.25), P. aeruginosa $44(0.5 / 8)$, A. baumannii $(0.25 / 2), H$. influenzae $(0.12 / 0.25), M$. catarrhalis 45 (0.03/0.06).According to the regression curve, zone diameter breakpoints 46 were 24 and $19 \mathrm{~mm}$ for MICs of 1 and $4 \mathrm{mg} / \mathrm{L}$.

47 Conclusion: This study confirms the potent in vitro activity of doripenem 48 against $P$. aeruginosa, Acinetobacter, Enterobacteriaceae, MSSA, MSCoNS 49 and respiratory pathogens. According to the EUCAST MIC breakpoints (mg/L) $50: \leq 1 />4$ for Enterobacteriaceae, $P$. aeruginosa and Acinetobacter and $\leq 1>1$ for 51 streptococci, pneumococci and Haemophilus, zone diameter breakpoints 52 could be $(\mathrm{mm}): \geq 24 /<19$ and $\geq 24 /<24$, respectively.

53 Keywords: doripenem, new carbapenem, in vitro activity, breakpoints 54 
C. Lascols

\section{INTRODUCTION}

56 The synthesis of new carbapenems remains an area of intense research

57 because of the broad-spectrum antibacterial activity of this chemical class [13]. Doripenem (formerly S-4661) is a recently approved parenteral $1 \beta$ methlycarbapenem, originally discovered by Shionogi \& Co., Ltd. (Osaka,

60 Japan), is currently being developed in the United States by Johnson and

61 Johnson Pharmaceutical Research and Development (Raritan, NJ) for the

62 treatment of hospitalized patients with serious systemic bacterial infections.

63 Doripenem has a methyl group at position 4 and a sulfamoylaminomethylated

64 pyrrolidinylthio group at position 3. Its in vitro antimicrobial potency is generally comparable to that of imipenem and meropenem, although doripenem is generally more active against Gram-positive organisms than meropenem and more active against Gram-negative organisms than

68 imipenem. The activity of doripenem against Pseudomonas isolates is slightly

69 better than that of other carbapenems. Doripenem is stable against human

70 renal DHP-I and thus does not require co-administration of cilastatin.

71 Like other carbapenems, doripenem has stability to many $\beta$-lactamases, but 72 remains labile to class $B$ enzymes known as metallo- $\beta$-lactamases.

73 Pharmacokinetic parameters resemble to meropenem with T1/2 of 74 approximately $1 \mathrm{~h}$; the serum protein binding is low (8-9\%).

75 Previous surveillance studies indicate that doripenem is active in vitro against 76 bacteria commonly associated with these indications $[4-9,3]$ and is effective in 77 vivo in murine models of bacteremia and pulmonary infection and in a rat 78 intra-uterine infection model $[10,9]$. Doripenem is an agent that will be specially used to treat infections caused by Gram-negative bacteria resistant 80 to a variety of antimicrobial agents. According to the European Medicines 81 Agency (EMEA), doripenem is indicated for the treatment of the following 82 infections: nosocomial pneumonia, including ventilator-associated 


\section{Lascols}

pneumonia, complicated intra-abdominal infections, complicated urinary tract infections, including complicated and uncomplicated pyelonephritis and cases with concurrent bacteraemia. FDA only approved doripenem for complicated intra-abdominal and urinary tract infection.

The aim of this multicenter study was to assess the in vitro activity of doripenem on a large number of isolates encountered in daily hospital practice in French hospitals. In addition, zone diameter breakpoints were determined for doripenem using the regression curve method by using the French national disk diffusion method calibrated to EUCAST MIC breakpoints, as recommended by EUCAST [11]

\section{MATERIALS AND METHODS}

\section{Bacterial strains}

Over a period of 3 months (October to December 2008), a total of 1,547 nonconsecutive single-patient isolates, were collected from 8 French hospitals (six teaching and two general hospitals). 20 strains of each frequently isolated species was requested from every institution enrolled in the study. For rarely isolated species, all the strains collected during the study period were included. Clinical isolates were collected from the main types of pathological specimens from in-patients in hospital wards representing the different medical and surgical specialities: $36.5 \%$ were isolated from general medical ward, $22.3 \%$ from general surgical ward, $19.3 \%$ from intensive care unit (ICU), $14.8 \%$ from emergency room and the remaining (7.1\%) from either other ward.

Isolates tested included: 173 S. aureus (90 methicillin-susceptible and 83 methicillin-resistant strains), 104 coagulase-negative staphylococci (CoNS) (50 methicillin-susceptible and 54 methicillin-resistant strains), 63 E. faecalis, 
11140 E. faecium, 83 S. pneumoniae, $60 \beta$-haemolytic streptococci; 19 viridans

112 group streptococci, 129 E. coli, 114 K. pneumoniae, 36 K. oxytoca, 90 E.

113 cloacae, 49 E. aerogenes, 31 Citrobacter spp., 114 P. mirabilis, 45 M.

114 morganii, 39 P. vulgaris, 10 P. rettgeri, 15 P. stuartii, 99 P. aeruginosa, 71

115 Acinetobacter spp, 30 S. maltophilia, 7 B. cepacia, 71 H. influenzae, $18 H$.

116 parainfluenzae and 36 M. catarrhalis. Isolates were obtained from urinary

117 tract infections (30\%), respiratory tract infections (19.9\%), blood cultures

118 (22.8\%), skin and soft tissues infections (11.9\%) and from other origin 119 (15.4\%).

\section{Antimicrobial Susceptibility Testing}

123 All tests were carried out using the reference broth microdilution method

124 according to the guidelines set forth in standard M7-A7 by the CLSI (formerly 125 NCCLS) [12]. Cation Adjusted Mueller-Hinton II Broth (i.e. BBL ${ }^{\mathrm{TM}}$, Becton 126 Dickinson, Le Pont de Claix, France) used for aerobic bacteria was modified

127 for streptococci by supplementation with $5 \%$ lysed horse blood, whereas for 128 Haemophilus the Haemophilus Test Medium (HTM) formulation (Oxoid,

129 Dardilly, France) was used. The same batch of medium was used by each 130 participating center. All tests followed CLSI technical details [12] for

131 incubation temperature and environment.

132 In order to determine the correlation between MICs and the inhibition zone

133 diameters, an agar diffusion antibiotic susceptibility testing was performed,

134 according to the recommendations of the Comité de l'Antibiogramme de la 135 Société Française de Microbiologie $[13,14]$. The discs with $10-\mu \mathrm{g}$ doripenem 136 were supplied by Johnson and Johnson Pharmaceutical Research, Raritan, 137 NJ, USA. 


\section{Lascols}

\section{Quality Control}

140 Analysis of doripenem MICs and inhibition zone diameters were performed

141 against four reference strains: $K$. pneumoniae U2A2189, K. pneumoniae

142 U2A2190, $P$. aeruginosa U2A2320 and $P$. aeruginosa U2A2321, provided by

143 the French National Reference Center of Antibiotics (CRAB), Institut Pasteur,

144 Paris. This indicated intercenter variabilities similar to those usually observed

145 for these techniques. All centers provided results which were not significantly

146 different from those of the reference center (with a 5\% risk of error) (data not

147 shown).

148 Results were examined to ensure that reported MICs were within acceptable

149 standards set by EUCAST [11] or CLSI [15] based on the following ATCC

150 quality control strains: S. aureus ATCC 29213, E. faecalis ATCC 29212, E.

151 coli ATCC 25922 and P. aeruginosa ATCC 27853.

\section{RESULTS}

\section{Staphylococci}

156 Table 1 presents the in vitro activity of doripenem against Gram-positive

157 microorganisms (542 isolates).

158 The in vitro activity of doripenem was examined against $173 \mathrm{~S}$. aureus

159 including 90 methicillin-resistant (MRSA) and 83 methicillin-susceptible

160 (MSSA) isolates. Doripenem was potent against MSSA isolates with

$161 \mathrm{MIC}_{50} / \mathrm{MIC}_{90}$ values of $0.03 / 0.25 \mathrm{mg} / \mathrm{L}$. By contrast they are $1 / 2 \mathrm{mg} / \mathrm{L}$ against

162 MRSA and it is admitted that MRSA have to be considered resistant to

163 carbapenems. The in vitro activity of doripenem was examined against 104

164 coagulase negative staphylococci including 54 methicillin-resistant (MR-

165 CoNS) and 50 methicillin-susceptible (MS-CoNS) isolates. Doripenem was as 


\section{Lascols}

166 potent against MS-CoNS isolates $\left(\mathrm{MIC}_{50 / 90}: 0.03 / 0.12 \mathrm{mg} / \mathrm{L}\right)$, as against $\mathrm{MS} S$.

167 aureus. MR-CoNS isolates with MICs of $2 / 8 \mathrm{mg} / \mathrm{L}$ have to be considered

168 resistant to carbapenems.

170 Enterococci

171 E. faecalis susceptibility testing results for doripenem showed that MICs

172 ranged from 0.06 to $8 \mathrm{mg} / \mathrm{L}$ with $\mathrm{MIC}_{50}$ and $\mathrm{MIC}_{90}$ values of 2 and $4 \mathrm{mg} / \mathrm{L}$. For

173 E. faecium, data showed that doripenem displayed no activity $\left(\mathrm{MIC}_{50 / 90}\right.$ :

$174 \quad 128 />128 \mathrm{mg} / \mathrm{L})$ against this species.

175

176 Streptococci

177 Doripenem MIC results for $S$. pneumoniae isolates were grouped by their

178 susceptibility category to penicillin (Table 1 ). The doripenem MIC values vary

179 according to the penicillin susceptibility with $\mathrm{MIC}_{50 / 90}$ results at $\leq 0.008 / 0.25$

$180 \mathrm{mg} / \mathrm{L}$ for penicillin-susceptible isolates and $0.25 / 0.5 \mathrm{mg} / \mathrm{L}$ for intermediate +

181 resistant isolates, respectively.

182 Against viridans group streptococci, MICs ranged from $\leq 0.008$ to $4 \mathrm{mg} / \mathrm{L}$ with

$183 \mathrm{MIC}_{50}$ and $\mathrm{MIC}_{90}$ values of 0.016 and $2 \mathrm{mg} / \mathrm{L}$, respectively. Doripenem

184 inhibited all isolates of $\beta$-haemolytic streptococci at MIC $\leq 0.03 \mathrm{mg} / \mathrm{L}$.

185

186 Enterobacteriaceae

187 Table 2 presents the in vitro activity of doripenem against Enterobacteriaceae

188 (672 isolates).

189 Doripenem was particularly active against members of the

190 Enterobacteriaceae: $70.8 \%$ of the isolates were inhibited by doripenem at

191 concentrations of $\leq 0.06 \mathrm{mg} / \mathrm{L}$. 


\section{Lascols}

192 The $\mathrm{MIC}_{50 \mathrm{~s}}$ and $\mathrm{MIC}_{90 \mathrm{~s}}$ for E. coli, Klebsiella, Proteus, Providencia,

193 Morganella, Citrobacter, and Enterobacter, ranged from 0.03 to $0.25 \mathrm{mg} / \mathrm{L}$

194 and 0.03 to $0.5 \mathrm{mg} / \mathrm{L}$, respectively.

195 Doripenem potency was high against E. coli and Klebsiella: $92.2 \%$ of E. coli

196 isolates and $75 \%$ of Klebsiella isolates had a doripenem MIC $\leq 0.03 \mathrm{mg} / \mathrm{L}$ and

$197 \leq 0.06 \mathrm{mg} / \mathrm{L}$, respectively. Isolates of E. cloacae and C. freundii were all

198 susceptible to doripenem (100\%) with $\mathrm{MICs}_{50 / 90}$ of $0.03 / 0.06 \mathrm{mg} / \mathrm{L}$ and

$1990.03 / 0.25 \mathrm{mg} / \mathrm{L}$ for cefotaxime-susceptible isolates and 0.12/0.25 mg/L and

$200 \quad 0.06 / 0.5 \mathrm{mg} / \mathrm{L}$ for cefotaxime-non susceptible isolates, respectively. The $P$.

201 mirabilis, $P$. vulgaris and $M$. morganii isolates the MICs of doripenem were

202 slightly higher but still low with $\mathrm{MIC}_{50 \mathrm{~s}}$ ranging from 0.12 to $0.25 \mathrm{mg} / \mathrm{L}$ and

$203 \quad \mathrm{MIC}_{90 \mathrm{~s}}$ values of $0.5 \mathrm{mg} / \mathrm{L}$.

204 Against cefotaxime-susceptible Enterobacteriaceae, doripenem had $\mathrm{MIC}_{50}$

205 and $\mathrm{MIC}_{90}$ of 0.06 and $0.25 \mathrm{mg} / \mathrm{L}$, respectively. The level of doripenem activity

206 against Enterobacteriaceae was essentially maintained against populations

207 not susceptible to broad-spectrum cephalosporins (i.e., non-susceptible to

208 cefotaxime). The $\mathrm{MIC}_{50}$ and $\mathrm{MIC}_{90}$ of doripenem against cefotaxime-non

209 susceptible enterobacteria were similar or between 1 or 2 doubling dilutions

210 when compared to those observed for cefotaxime-susceptible isolates,

211 whatever the bacterial species was (Table 2). Against ESBL screen-positive

212 isolates of Enterobacteriaceae $(n=43)$, doripenem maintained the same level

213 of activity as that observed against Enterobacteriaceae overall $\left(\mathrm{MIC}_{50 / 90}\right.$ :

$2140.06 / 0.25 \mathrm{mg} / \mathrm{L})$. Among $\mathrm{ESBL}$ isolates, $69.8 \%$ of isolates were inhibited by

215 doripenem at concentrations $\leq 0.06 \mathrm{mg} / \mathrm{L}$.

216

217 Pseudomonas aeruginosa and Acinetobacter spp

218 Table 3 presents the in vitro activity of doripenem against non fermentative

219 bacilli (207 isolates). 


\section{Lascols}

220 Doripenem demonstrated widely variable activity against the tested non-

221 fermentative Gram-negative bacilli, as shown by $83.1 \%$ susceptibility at

222 EUCAST breakpoint of $\leq 1 \mathrm{mg} / \mathrm{L}$ for Acinetobacter and $71.7 \%$ for $P$.

223 aeruginosa but for $B$. cepacia and $S$. maltophilia $\mathrm{MIC}_{50 / 90}$ were $2 / 8$ and

$224>128 / 128 \mathrm{mg} / \mathrm{L}$.

225 According to the EUCAST breakpoints of $\leq 1$ and $>4 \mathrm{mg} / \mathrm{L}, 71.7 \%$ of the $P$.

226 aeruginosa were susceptible, $15.2 \%$ were intermediate and $13.1 \%$ were

227 resistant.

228 Doripenem activity was evaluated against imipenem-susceptible and non

229 susceptible $P$. aeruginosa isolates (Table 3 ). The $\mathrm{MIC}_{50 / 90 \text { s }}$ of doripenem for

230 imipenem-susceptible isolates were of 0.25 and $2 \mathrm{mg} / \mathrm{L}$ and $87 \%$ of them

231 were susceptible to doripenem.

232 Against imipenem-non susceptible isolates, MICs of doripenem were notably

233 increased, as the $\mathrm{MIC}_{50}$ and $\mathrm{MIC}_{90}$ were 8 and $16 \mathrm{mg} / \mathrm{L}$ respectively but with a

234 wide range of MICs $(0.12$ to $64 \mathrm{mg} / \mathrm{L})$. Of note, $18.2 \%$ of imipenem-resistant

235 isolates were susceptible to doripenem.

236 Doripenem was active against all imipenem-susceptible $A$. baumannii isolates

237 with $\mathrm{MIC}_{50 / 90}$ : of 0.25 and $1 \mathrm{mg} / \mathrm{L}$ and intermediate or resistant against

238 imipenem-resistant isolates with MIC values range from 2 to $32 \mathrm{mg} / \mathrm{L}$.

240 Haemophilus spp and M. catarrhalis

241 Table 4 presents the in vitro activity of doripenem against respiratory Gram-

242 negative pathogens (126 isolates).

243 Doripenem has potent in vitro activity against $H$. influenzae, $H$.

244 parainfluenzae, and M. catarrhalis. The MIC range for doripenem against the

$24571 \mathrm{H}$. influenzae was $\leq 0.008$ to $1 \mathrm{mg} / \mathrm{L} ; \mathrm{MIC}_{50}$ and $\mathrm{MIC}_{90}$ values were exactly

246 the same for ampicillin-susceptible isolates as for ampicillin non-susceptible

247 isolates $\left(\mathrm{MIC}_{50 / 90}=0.12 / 0.25 \mathrm{mg} / \mathrm{L}\right)$. 
248 The MIC range for doripenem against the $18 \mathrm{H}$. parainfluenzae isolates tested

249 was $\leq 0.008$ to $0.12 \mathrm{mg} / \mathrm{L}$, doripenem potency was almost similar for ampicillin

250 susceptible or non-susceptible isolates (Table 5).

251 The MIC range for doripenem towards the $36 \mathrm{M}$. catarrhalis isolates was

$252 \leq 0.008$ to $0.06 \mathrm{mg} / \mathrm{L} ; \mathrm{MIC}_{50}$ and $\mathrm{MIC}_{90}$ values were 0.03 and $0.06 \mathrm{mg} / \mathrm{L}$,

253 respectively,

254 Finally, all the 125 isolates $(100 \%)(71 \mathrm{H}$. influenzae, $18 \mathrm{H}$. parainfluenzae

255 and $36 M$. catarrhalis) were susceptible to doripenem according to the

256 EUCAST breakpoint of $\leq 1 \mathrm{mg} / \mathrm{L}$.

\section{Correlation between inhibition zone diameters and MICs}

261 The regression curve between the MIC values (logarithm to the base 2) on

262 the x-axis and the inhibition diameters (arithmetic scale) in the $y$-axis was

263 determined by the least-square method on 1,547 isolates whose distribution

264 is depicted in Figure 1, where the width of the lines is proportional to the 265 number of isolates.

266 The zone diameters breakpoints can then be deduced from the doripenem

267 EUCAST MIC breakpoints: 1/4 for Enterobacteriaceae, Pseudomonas and

268 Acinetobacter and $1 / 1$ for streptococci (including S. pneumoniae), and

269 Haemophilus spp and M. catarrhalis.

270 Zone diameter breakpoints with a $10-\mu \mathrm{g}$ doripenem disc content could thus

271 be 24 and $19 \mathrm{~mm}$ ( $\geq 24$, susceptible; $19-23$, intermediate and $<19$, resistant)

272 for Enterobacteriaceae, Pseudomonas and Acinetobacter and $24 \mathrm{~mm}(\geq 24$,

273 susceptible and <24, resistant) for streptococci (including S. pneumoniae),

274 Haemophilus spp and M. catarrhalis. 


\section{Lascols}

275 For instance, using a zone diameter breakpoint of $\geq 24 \mathrm{~mm}$ to denote

276 susceptibility, a false susceptibility rate (Rs) of $0.32 \%$ (5 isolates) and a false

277 resistant $(\mathrm{Sr})$ rate of $0.19 \%$ (3 isolates) were seen in each case (Figure 1)

\section{DISCUSSION}

280 Doripenem was potent againt oxacillin-susceptible staphylococci with the 281 same $\mathrm{MIC}_{50 / 90}$ than imipenem [8]. Nevertheless, according to the EUCAST

282 recommendations, "susceptibility of staphylococci to carbapenems is inferred 283 from the methicillin susceptibility". So methicillin-resistant staphylococci have 284 to be considered resistant to carbapenems including doripenem. Most 285 enterococci isolates were not susceptible to doripenem.

286 Doripenem was potent against penicillin-susceptible S. pneumoniae. The 287 decrease of its activity coincided with decreased susceptibility to penicillin as 288 already shown in literature [16].

289 Doripenem was highly potent against all Enterobacteriaceae isolates tested, 290 including those resistant to "advanced-generation" cephalosporins and 291 screen-positive ESBL isolates. This pattern of doripenem activity against

292 Enterobacteriaceae was similar to that reported in previous studies [4-7,9].

293 Doripenem maintained the same activity against all cefotaxime-non

294 susceptible or susceptible isolates of Enterobacteriaceae and also against

295 ESBL positive isolates with the exception of $E$. cloacae for which the 296 doripenem $\mathrm{MIC}_{50 / 90}$ were four-fold higher for cefotaxime-non susceptible 297 isolates in comparison to cefotaxime susceptible isolates .

298 The maintained activity of doripenem and other carbapenems against 299 enterobacteria resistant to other $\beta$-lactams is largely due to their stability to 300 hydrolysis by $\beta$-lactamases commonly encountered among these organisms.

301 Against $P$. aeruginosa imipenem-susceptible. Doripenem was highly potent, 302 as already shown in other studies $[4,5,7,17,9,3]$. It is two- and four-fold more 


\section{Lascols}

303 potent than meropenem and imipenem respectively $[8,16]$. Against imipenem-

304 resistant isolates with $\mathrm{MICs} \geq 8 \mathrm{mg} / \mathrm{L}, 22.4 \%$ have $\mathrm{MIC}$ of doripenem $<4 \mathrm{mg} / \mathrm{L}$

305 [7].

306 Overall, $71.7 \%$ of isolates tested in this study were susceptible to doripenem.

307 Though the in vitro activities of doripenem and imipenem show parallel

308 variation against Gram-negative bacilli as described above, imipenem has

309 been shown to be an acceptable surrogate marker for determining the

310 susceptibility of Gram-negative clinical isolates to carbapenems including

311 doripenem [18]. However, this type of testing does not account for clinical

312 isolates which are non-susceptible to imipenem but remain susceptible to

313 doripenem. For example, $18 \%$ of $P$. aeruginosa isolates tested in this study

314 as non-susceptible to imipenem were susceptible to doripenem.

315 This is consistent with the view that doripenem is less affected by the

316 deficiency of OprD porin protein than imipenem [19]. On the other hand, a few

317 imipenem-susceptible strains (3\%) have MICs of doripenem $>1 \mathrm{mg} / \mathrm{L}$ and are

318 thus considered non-susceptible according to EUCAST MIC breakpoints,

319 what can be mainly explained by the difference between the susceptibility

320 breakpoints concentrations established by EUCAST for imipenem and

321 doripenem ( $\leq 4$ and $\leq 1 \mathrm{mg} / \mathrm{L}$, respectively). Nevertheless, it was reported that

322 doripenem, even if in a lesser degree than meropenem, is affected by the

323 efflux mechanism and overexpression of efflux pumps in $P$. aeruginosa

324 results in moderate resistance to doripenem, whereas imipenem largely

325 escapes this mechanism [20].

326 Although cross-resistance exists between imipenem and doripenem, like

327 meropenem, doripenem appears to be in vitro more active than imipenem

328 against OprD-deficient $P$. aeruginosa strains.

329 The activity of doripenem against imipenem-susceptible $A$. baumannii was

330 similar to that of imipenem-susceptible $P$. aeruginosa but in contrast, 


\section{Lascols}

331 doripenem was not active against any imipenem-non susceptible isolates of

332 Acinetobacter spp., which may be due to several mechanisms of resistance

333 present in these strains such as carbapenemase phenotype, membrane

334 impermeability or variable porin/outer membrane protein expression [21].

335 No activity was observed against $S$. maltophilia isolates, and B. cepacia was

336 inconstantly susceptible to doripenem (only $28.6 \%$ susceptible isolates).

337 Doripenem was also active against respiratory pathogens as $H$. influenzae, $H$.

338 parainfluenzae or $M$. catarrhalis, regardless of ampicillin resistance.

\section{CONCLUSION}

343 Doripenem is a broad-spectrum carbapenem with a good in vitro activity

344 against Gram-positive cocci and against challenging Gram-negative

345 pathogens, including resistant Enterobacteriaceae and $P$. aeruginosa. This

346 study performed on a large number of isolates confirms its potent in vitro

347 activity against such clinically isolates. Based on the activity profile presented

348 in this study and others, doripenem appears to be a promising new agent for

349 the treatment of infections caused by severe Gram-negative pathogens

350 commonly encountered in the hospital including cephalosporin resistant

351 enteric bacilli and multidrug-resistant $P$. aeruginosa or Acinetobacter spp.

352 Because its primary use will be associated with the hospital where plasmid-

353 mediated resistance to carbapenems has already been documented among

354 some Gram-negative bacterial isolates, it is important to continue to monitor

355 the activity of doripenem throughout its clinical development and after its 356 introduction into clinical use. 
C. Lascols

357 This study allowed us to determine zone diameter breakpoints, which are 24

358 and $19 \mathrm{~mm}$ for MICs of 1 and $4 \mathrm{mg} / \mathrm{L}$, used for clinical categorization according to

359 the EUCAST MIC breakpoints.

360

361

362

363

364

365

366

367

368

369 Acknowledgements

370 We would like to express our appreciation to the following people for expert

371 technical support: M. Auzou, S. Brémont, A. Charles, C. Delaunay, A. Ly, P.

372 McGill and M. Rougier.

373

374 Financial support

375 This study was funded by Janssen-Cilag, Issy-Les-Moulineaux, France

376

377 Potential conflicts of interest:

378 No conflict for all authors is declared.

379

380 


\section{REFERENCES}

382

383 1. Nomura S, Nagayama A. In vitro antibacterial activity of S-4661, a new

384 parenteral carbapenem, against urological pathogens isolated from patients

385 with complicated urinary tract infections. J Chemother 2002;14(2):155-60.

386 2. Ohiba F, Nakamura-Kamigo M, Watanabe N, Katsu K. In vitro and in vivo

387 antibacterial activities of ER-35786, a new antipseudomonal carbapenem.

388 Antimicrob Agents Chemother 1997;41:298-307.

389 3. Watanabe A, Takahashi $\mathrm{H}$, Kikuchi $\mathrm{T}$, et al. Comparative in vitro activity of

390 S-4661, a new parenteral carbapenem, and other antimicrobial agents

391 against respiratory pathogens. Chemotherapy 2000;46(3):184-7.

392 4. Brown SD, Traczewski MM. Comparative in vitro antimicrobial activity of a

393 new carbapenem, doripenem: tentative disc diffusion criteria and quality

394 control. J Antimicrob Chemother 2005;55(6):944-9.

395 5. Fritsche TR, Stilwell MG, Jones RN. Antimicrobial activity of doripenem (S-

396 4661): a global surveillance report (2003). Clin Microbiol Infect

397 2005;11(12):974-84.

398 6. Ge Y, Wikler MA, Sahm DF, Blosser-Middleton RS, Karlowsky JA. In vitro

399 antimicrobial activity of doripenem, a new carbapenem. Antimicrob Agents

400 Chemother 2004;48(4):1384-96.

401 7. Jones RN, Huynh HK, Biedenbach DJ. Activities of doripenem (S-4661)

402 against drug-resistant clinical pathogens. Antimicrob Agents Chemother $403 \quad 2004 ; 48(8): 3136-40$.

404 8. Jones RN, Huynh HK, Biedenbach DJ, Fritsche TR, Sader HS. Doripenem

405 (S-4661), a novel carbapenem: comparative activity against contemporary 406 pathogens including bactericidal action and preliminary in vitro methods 407 evaluations. J Antimicrob Chemother 2004;54(1):144-54. 
408 9. Tsuji M, Ishii Y, Ohno A, Miyazaki S, Yamaguchi K. In vitro and in vivo

409 antibacterial activities of S-4661, a new carbapenem. Antimicrob Agents

410 Chemother 1998;42(1):94-9.

411 10. Mikamo H, Izumi K, Hua YX, Hayasaki $\mathrm{Y}$, Sato $\mathrm{Y}$, Tamaya T. In vitro and

412 in vivo antibacterial activities of a new injectable carbapenem, S-4661,

413 against gynecological pathogens. J Antimicrob Chemother 2000;46(3):471-4.

414 11. European Committee on Antimicrobial Susceptibility Testing. Clinical

415 Breakpoints. 2009. http://www.eucast.org.

416 12. Clinical Laboratory Standards Institute. Methods for Dilution Antimicrobial

417 Susceptibility Tests for Bacteria that Grow Aerobically. 7th Edition. Approved

418 Standard M7-A7. CLSI, Wayne, PA, USA, 2006.

419 13. Comité de l'Antibiogramme de la Société Française de Microbiologie.

420 Communiqué 2009. Société Française de Microbiologie.

421 http://www.sfm.asso.fr

422 14. Courvalin P., Soussy C.J. Report of the Comité de l'Antibiogramme de la 423 Société Française de Microbiologie. Clinical Microbiology and Infection. 424 1996,2, suppl. 1, SI-S49.

425 15. Clinical Laboratory Standards Institute. Performance Standards for 426 Antimicrobial Susceptibility Testing. 17th Informational Supplement M100-17. 427 CLSI, Wayne, PA, USA, 2007.

428 16. Pillar CM, Torres MK, Brown NP, Shah D, Sahm DF. In vitro activity of 429 doripenem, a carbapenem for the treatment of challenging infections caused 430 by gram-negative bacteria, against recent clinical isolates from the United 431 States. Antimicrob Agents Chemother 2008;52(12):4388-99.

432 17. Jones RN, Sader HS, Fritsche TR. Comparative activity of doripenem and 433 three other carbapenems tested against Gram-negative bacilli with various 
C. Lascols

434 beta-lactamase resistance mechanisms. Diagn Microbiol Infect Dis $435 \quad 2005 ; 52(1): 71-4$.

436 18. Jones RN, Sader HS, Fritsche TR, Janechek MJ. Selection of a surrogate

437 beta-lactam testing agent for initial susceptibility testing of doripenem, a new

438 carbapenem. Diagn Microbiol Infect Dis 2007;59(4):467-72.

439 19. Mushtaq S, Ge Y, Livermore DM. Doripenem versus Pseudomonas

440 aeruginosa in vitro: activity against characterized isolates, mutants, and

441 transconjugants and resistance selection potential. Antimicrob Agents

442 Chemother 2004;48(8):3086-92.

443 20. Masuda N, Sakagawa E, Ohya S, Gotoh N, Tsujimoto H, Nishino T.

444 Substrate specificities of MexAB-OprM, MexCD-OprJ, and MexXY-oprM

445 efflux pumps in Pseudomonas aeruginosa. Antimicrob Agents Chemother $446 \quad 2000 ; 44(12): 3322-7$.

447 21. Poirel L, Nordmann P. Carbapenem resistance in Acinetobacter

448 baumannii: mechanisms and epidemiology. Clin Microbiol Infect $4492006 ; 12(9): 826-36$.

450

451

452

453

454

455

456 
487 
Table 1. Antimicrobial activity of doripenem tested against Grampositive microorganisms (572 isolates)

490

\section{Organism (no. tested)}

Staphylococcus aureus (173)

OXA S (90)

OXA R (83)

Coagulase Negative Staphylococci (104)

OXA S (50)

OXA R (54)

Enterococcus faecalis (63)

Enterococcus faecium (40)

Streptococcus pneumoniae (83)

PEN S (48)

PEN I + R(35)

Streptococci A, B, C and G (60)

Other Streptococci (49)

0.03
2

2

128

$\leq 0.008$

0.25

0.03

0.5

0.12
8

$\leq 0.008-0.12$

0.25-64

$4 \quad 0.06-8$

$\leq 0.008$

$\leq 0.008$

$\leq 0.008-0.03$

96.

0.016

OXA: oxacillin, PEN: penicillin

nd: not determined

*Determination of doripenem susceptibility according MIC EUCAST breakpoints (not available for

staphylococci and enterococci, $\leq 1 \mathrm{mg} / \mathrm{L}$ for streptococci) 
Table 2. Antimicrobial activity of doripenem tested against Enterobacteriaceae (672 isolates)

Organism (no. tested)

All Enterobacteriaceae (672)
CTX S (578)

CTX R (94)

\begin{tabular}{cccc}
\hline \multicolumn{5}{c}{ MIC (mg/L) } \\
\hline $50 \%$ & $90 \%$ & Range & $\begin{array}{c}\% \\
\text { Susceptible* }\end{array}$
\end{tabular}

Escherichia coli (129)

CTX S (118)

CTX R (11)

$\begin{array}{llc}0.06 & 0.25 & \leq 0.008-2 \\ 0.06 & 0.25 & 0.016-2\end{array}$

99.8

Citrobacter freundii (31)

CTX S (22)

CTX R (9)

$\begin{array}{lll}0.03 & 0.03 & \leq 0.008-0.12 \\ 0.03 & 0.06 & 0.016-0.06\end{array}$

100

Klebsiella pneumoniae (114)

CTX S (97)

CTX R (17)

0.03

0.25

$\leq 0.008-0.5$

0.06

0.5

0.03-0.5

100

Klebsiella oxytoca (36)

CTX S (35)

CTX R (1)

$\begin{array}{llc}0.03 & 0.06 & \leq 0.008-0.12 \\ 0.03 & 0.06 & 0.03-0.5\end{array}$

100

Enterobacter cloacae (90)

CTX S (57)

CTX R (33)

$\begin{array}{ccc}0.03 & 0.06 & \leq 0.008-0.5 \\ \text { nd } & \text { nd } & \text { nd }\end{array}$

100

Enterobacter aerogenes (49)

CTX S (36)

CTX R (13)

0.03

0.12

0.06

0.25

$\leq 0.008-0.25$
$0.016-0.5$

100

Proteus mirabilis (114)

CTX S (112)

CTX R (2)

$0.06 \quad 0.12 \leq 0.008-0.25$

0.12

0.25

0.06- 0.25

100

Morganella morganii (46)

CTX S (42)

CTX R (4)

$\begin{array}{ccc}0.12 & 0.5 & \leq 0.008-2 \\ \text { nd } & \text { nd } & \text { nd }\end{array}$

99.1

Proteus vulgaris (38)

CTX S (37)

CTX R (1)

0.25

0.5

$\leq 0.008-1$

0.25

0.5

0.12-0.5

100

Providencia stuartii (15)

CTX S (13)

CTX R (2)

$\begin{array}{ccc}\begin{array}{c}0.25 \\ \text { nd }\end{array} & \begin{array}{c}0.5 \\ \text { nd }\end{array} & \begin{array}{c}\leq 0.008-1 \\ \text { nd }\end{array} \\ 0.12 & \begin{array}{c}0.25 \\ \text { nd }\end{array} & \begin{array}{c}\leq 0.008-0.25 \\ \text { nd }\end{array}\end{array}$

100

Providencia rettgeri (10) 


\begin{tabular}{llll}
\hline CTX S (10) & 0.06 & $0.12 \quad \leq 0.008-0.25$
\end{tabular}

\section{CTX: cefotaxime}

nd: not determined

*Determination of doripenem susceptibility according MIC EUCAST breakpoints $(\leq 1 \mathrm{mg} / \mathrm{L})$

Table 3. Antimicrobial activity of doripenem tested against non

fermentative bacilli (207 isolates)

\begin{tabular}{lcccc}
\hline \multicolumn{1}{c}{ Organism (no. tested) } & \multicolumn{5}{c}{ MIC (mg/L) } \\
& $\mathbf{5 0 \%}$ & $\mathbf{9 0} \%$ & Range & \% Susceptible* \\
\cline { 2 - 5 } & & & & \\
Pseudomonas aeruginosa (99) & 0.25 & 2 & $0.016-8$ & 71.7 \\
IPM S (77) & 8 & 16 & $0.12-64$ & \\
IPM R (22) & & & & \\
Acinetobacter baumannii (71) & 0.25 & 1 & $0.03-4$ & 83.1 \\
IPM S (65) & nd & nd & $2-32$ & \\
IPM R (6) & $>128$ & $>128$ & $64->128$ & 0 \\
Stenotrophomonas maltophilia (30) & 2 & 8 & $1-128$ & 28.6 \\
Burkholderia cepacia (7) & & & &
\end{tabular}

IPM: imipenem

nd: not determined

*Determination of doripenem susceptibility according MIC EUCAST breakpoints $(\leq 1 \mathrm{mg} / \mathrm{L})$

536

537

538

539

540

541

542

543

544

545

546

547

548

549

550

551

552

553

554

555

556

557

558

559

560

561

562 
563

564

565

566

567

568

569

570

571

Table 4. Antimicrobial activity of doripenem tested against Gramnegative respiratory pathogens (125 isolates)

Organism (no. tested)

$\operatorname{MIC}(\mathrm{mg} / \mathrm{L})$

\begin{tabular}{lcccr}
\hline & $\mathbf{5 0 \%}$ & $\mathbf{9 0} \%$ & Range & $\%$ Susce \\
\cline { 2 - 5 } Haemophilus influenzae (71) & 0.12 & 0.25 & $\leq 0.008-1$ & \\
AMP S (54) & 0.12 & 0.25 & $\leq 0.008-1$ & 100 \\
AMP R (17) & & &
\end{tabular}

Haemophilus parainfluenzae (18)

AMP S (9)

AMP R (9)

0.12

0.12

$\leq 0.008-0.12$

0.06

0.12

$\leq 0.008-0.12$

94.

Moraxella catarrhalis (36)

AMP S (2)

AMP R (34)

nd

nd

$0.016-0.03$

0.03

0.06

$\leq 0.008-0.06$

100

AMP: ampicillin

nd: not determined

${ }^{*}$ Determination of doripenem susceptibility according MIC EUCAST breakpoints $(\leq 1 \mathrm{mg} / \mathrm{L}$ )

575

576

577

578

579

580

581

582

583

584

585

586

587

588

589

590

591

592

593

594

595

596

597

598

599

600

601 
C. Lascols

602

603 